\title{
PENDUGAAN STOK IKAN TONGKOL DI SELAT MAKASSAR SULAWESI SELATAN
}

Edy H.P. Melmambessy
ABSTRAK
Staf Pengajar Univ. Musamus-Merauke, e-mail : edymelmambessy@yahoo.co.id
Ikan tongkol termasuk dalam golongan ikan tuna kecil, dan selalu
bergerombol. Jenis ikan tongkol yang ada di Selat Makassar Sulawesi
Selatan adalah Euthynnus affinis, Auxis thazard, dan Auxis rochei. Data
produksi tahun 1999-2007 Dinas Kelautan dan Perikanan Provinsi Sulawesi
Selatan menunjukkan bahwa terjadi peningkatan produksi dan jumlah
nelayan untuk melakukan penangkapan ikan tongkol. Permintaan ikan yang
meningkat tentu berpengaruh positif bagi peningkatan pendapatan nelayan,
namun perlu disadari bahwa peningkatan permintaan sumberdaya tersebut
selalu diikuti tekanan untuk melakukan eksploitasi semakin intensif. Tujuan
penulisan adalah untuk mengetahui nilai lestari-Maksimum Sustainable
Yield (MSY) dan Effort Optimal (Fopt.) ikan tongkol di perairan Selat
Makassar Sulawesi Selatan serta mengetahui apakah telah terjadi
overfishing atau belum dalam pemanfatan ikan tongkol.
Pengumpulan data dilakukan pada bulan Mei 2010 bertempat di Dinas
Kelautan dan Perikanan Provinsi Sulawesi Selatan. Penelitian ini
dilaksanakan dengan cara menganalisis data sekunder tahun
1999 sampai 2007 yang diperoleh dari Dinas Kelautan dan Perikanan
Provinsi Sulawesi Selatan dengan model Schaefer dan Fox.
Dari hasil penelitian disimpulkan bahwa : 1) nilai lestari (MSY) ikan
tongkol di Selat Makassar Sulawesi Selatan adalah 4.069,75 ton per tahun
dengan penangkapan optimum (Fopt.) 1.666.666,67 trip per tahun.
2) Keberadaan populasi ikan Tongkol di perairan Selat Makassar Sulawesi
Selatan telah mengalami over fishing, dimana hasil penangkapan pada
tahun 2007 sebesar 6.139.6 ton telah melewati nilai lestari (MSY) ikan
tongkol sebesar 4.069,75 ton per tahun.

\section{Kata Kunci : Ikan tongkol, Selat Makassar, MSY, Overfishing}

\section{PENDAHULUAN}

\subsection{Latar Belakang}

Salah satu potensi laut Indonesia adalah potensi sumberdaya ikan, yang meliputi : sumberdaya ikan pelagis besar, sumberdaya ikan pelagis kecil, sumberdaya udang penaeid dan krustasea lainnya, sumberdaya ikan demersal, sumberdaya moluska dan teripang, sumberdaya cumicumi, sumberdaya benih alam komersial, sumberdaya karang, sumberdaya ikan konsumsi perairan karang, sumberdaya ikan hias, sumberdaya penyu laut, sumberdaya mammalia laut, dan sumberdaya rumput laut (Mallawa, 2006).

Ikan tongkol termasuk dalam golongan ikan tuna kecil, dan selalu bergerombol. Jenis ikan tongkol yang ada di Selat Makassar adalah Euthynnus affinis, Auxis thazard, dan Auxis rochei (Mallawa, 2006).

Wilayah perairan Selat Makassar Sulawesi Selatan termasuk dalam WPP 6 WPP-RI 713, memiliki sumberdaya ikan 
yang berlimpah dan beraneka ragam. Dari data produksi tahun 1999-2007 Dinas Kelautan dan Perikanan Propinsi Sulawesi Selatan menunjukkan bahwa terjadi peningkatan produksi dan jumlah nelayan untuk melakukan penangkapan ikan tongkol. Seiring dengan meningkatnya jumlah penduduk dan kebutuhan pangan dan gizi yang lebih baik sangat memacu tingginya permintaan masyarakat pada kebutuhan konsumsi ikan. Permintaan ikan yang meningkat tentu berpengaruh positif bagi peningkatan pendapatan nelayan, namun perlu disadari bahwa peningkatan permintaan sumberdaya tersebut selalu diikuti tekanan untuk melakukan eksploitasi semakin intensif. Sampai saat ini hasil tangkapan khususnya ikan tongkol di Selat Makasar Sulawesi Selatan telah mencapai 19.162,29 ton pada tahun 19992007. Melihat potensi sumberdaya yang ada, maka tentunnya pengelolaan perikanan menjadi alat yang sangat penting untuk menjaga keberlanjutan sumberdaya ikan tongkol.

Bagaimana kondisi lestari (Maximum Sustainable Yieald) dan upaya pemanfaatan ikan tongkol di Selat Makassar supaya tetap bertanggungjawab dan berkelanjutan? Untuk menjawab pertanyaan itu, maka dilakukan kajian pendugaan stok ikan tongkol di Selat Makasar Sulawesi Selatan yang meliputi Kabupaten/Kota : Makassar, Maros, Pangkep, Parepare, Barru dan Pinrang.

\subsection{Tujuan dan Kegunaan Penulisan}

Tujuan penulisan adalah untuk mengetahui nilai lestari- MSY dan Fopt. ikan tongkol di perairan Selat Makassar Sulawesi Selatan serta mengetahui apakah telah terjadi over fishing pada perairan. Sedangkan kegunaan dari penulisan adalah memberikan informasi secara ilmiah kepada Dinas Kelautan dan Perikanan Propinsi Sulawesi Selatan dan Dinas Kelautan dan Perikanan Kota/Kabupaten : Makassar, Maros, Pangkep, Barru, ParePare dan Pinrang serta pihak terkait tentang kondisi lestari (MSY) sumberdaya ikan tongkol saat ini di perairan Selat Makassar Sulawesi Selatan dan diharapakan kebijakan manajemen pengelolaan ikan tongkol secara bertanggungjawab dan berkelanjutan agar stok ikan tongkol tetap lestari.

\section{METODOLOGI PENELITIAN}

\subsection{Waktu dan Tempat}

Pengumpulan data dilakukan pada bulan Mei 2010 bertempat di Dinas Kelautan dan Perikanan Provinsi Sulawesi Selatan.

\subsection{Metode Pengumpulan Data}

Penelitian ini dilaksanakan dengan cara menganalisis data sekunder dari tahun 1999 hingga tahun 2007 yang diperoleh dari Dinas Kelautan dan Perikanan Provinsi Sulawesi Selatan. Data sekunder yang dikumpulkan meliputi : data hasil tangkapan dan data trip dari setiap alat tangkap yang digunakan menangkap ikan tongkol di Selat Makassar Sulawesi Selatan pada Kabupaten/Kota : Makassar, Maros, Pangkep, Pare-pare, Barru dan Pinrang. Selain itu data juga dilengkapi dan ditunjang dengan studi literatur.

\subsection{Metode Penelitian}

Metode penelitian yang digunakan adalah Metode Diskriptif, dimana tujuannya adalah untuk membuat gambaran mengenai situasi atau kejadian, sehingga metode ini berkehendak mengadakan akumulasi data dasar belaka (Nazir, 2003).

\subsection{Analisa Data}

Data yang diperoleh berupa data produksi, data trip, data alat tangkap yang digunakan setiap tahun mulai dari tahun 1999-2007. Data produksi lestari yang diperoleh dijadikan sebagai bahan informasi untuk menganalisa keberadaan ikan tongkol di perairan Selat Makassar Sulawesi Selatan.

1. Standarisasi Effort

Unit effort sejumlah armada penangkapan ikan dengan alat tangkap dan waktu tertentu dikonversi ke dalam satuan 
"boat-days" (trip). Pertimbangan yang digunakan adalah :
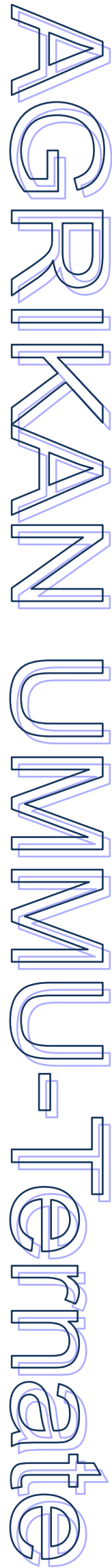

a. Respon stock terhadap alat tangkap standar akan menentukan status sumberdaya selanjutnya berdampak pada status perikanan alat tangkap lain,

b. Total hasil tangkap ikan per unit effort alat tangkap standar lebih dominan dibanding alat tangkap lain, dan

c. Daerah penangkapan alat tangkap standar meliputi dan atau berhubungan dengan daerah penangkapan alat tangkap lain.

Prosedur standarisasi alat tangkap ke dalam satuan baku unit alat tangkap standar, dapat dilakukan sebagai berikut :

a. Alat tangkap standar yang digunakan mempunyai CPUE terbesar dan memiliki nilai faktor daya tangkap (fishing power index, FPI) sama dengan 1. Nilai FPI dapat diperoleh melalui persamaan (Gulland, 1983):

$$
\begin{aligned}
& \text { CPUE }_{r}=\frac{\text { Catch }_{r}}{\text { Effort }_{r}} \\
& C P U E_{s}=\frac{\text { Catch }_{s}}{\text { Effort }_{s}} \\
& F P I_{i}=\frac{\text { CPUE }_{r}}{\text { CPUE }_{S}}
\end{aligned}
$$

Dimana :

$\mathrm{r}=1,2,3, \ldots, \mathrm{P}$ (alat tangkap yang distandarisasi)

$\mathrm{s}=1,2,3, \ldots, \mathrm{Q}$ (alat tangkap standar)

$\mathrm{i}=1,2,3, \ldots, \mathrm{K}$ (Jenis alat tangkap)

CPUE $_{\mathrm{r}}=$ total hasil tangkapan (catch) per upaya tangkap (effort) dari alat tangkap $r$ yang akan distandarisasi (ton/trip).

$\mathrm{CPUE}_{\mathrm{s}}=$ total hasil tangkapan (catch) per upaya tangkap (effort) dari alat tangkap s yang dijadikan standar (ton/trip).

$\mathrm{FPI}_{\mathrm{i}} \quad=$ fishing power index dari alat tangkap i (yang distandarisasi dan alat tangkap standar)

b. Nilai FPIi digunakan untuk menghitung total upaya standar, yakni :
$E=\sum_{i=1}^{i} F P I_{i} \cdot E_{i}$

dimana :

$\mathrm{E}=$ total effort atau jumlah upaya tangkap dari alat tangkap yang distandarisasi dan alat tangkap standar (trip)

$\mathrm{E}_{\mathrm{i}}=$ effort dari alat tangkap yang distandarisasi dan alat tangkap standar (trip)

2. Maximum Sustainable Yield

Estimasi potensi sumberdaya perikanan tangkap didasarkan atas jumlah hasil tangkapan ikan yang didaratkan pada suatu wilayah dan variasi alat tangkap per trip. Prosedur estimasi dilakukan dengan cara (Sparre dan Venema, 1999) :

a. Menghitung hasil tangkapan per upaya tangkap (CPUE), melalui persamaan :

$\mathrm{CPUE}_{n}=\frac{\mathrm{Catch}_{n}}{E_{n}}, n=1,2,3, \ldots, M$,

dimana :

CPUE $_{n}=$ total hasil tangkapan per upaya penangkapan yang telah distandarisasi dalam tahun $\mathrm{n}$ (ton/trip)

Catch $_{\mathrm{n}}=$ total hasil tangkapan dari seluruh alat dalam tahun $\mathrm{n}$ (ton)

En = total effort atau jumlah upaya tangkap dari alat tangkap yang distandarisasi dengan alat tangkap standar dalam tahun $\mathrm{n}$ (trip).

b. Melakukan estimasi parameter alat tangkap standar dengan menggunakan model Schaefer berikut :

$\mathrm{CPUE}_{\mathrm{n}}=\mathrm{a}-\beta \mathrm{E} / \mathrm{Catchn}=\mathrm{a} \mathrm{En}-\beta \mathrm{En}^{2}$

dimana :

CPUE $_{n}=$ total hasil tangkapan per upaya setelah distandarisasi pada tahun $\mathrm{n}$ (ton/trip)

$\mathrm{E}_{\mathrm{n}} \quad=$ total effort standar pada tahun n (trip/tahun)

a dan $\mathrm{R}=$ konstanta dan koefisien parameter dari model Schaefer 
Persamaan di atas, dihitung dengan menggunakan metode regresi linear sederhana (Ordinary Least Square, OLS).

c. Melakukan estimasi effort optimum pada kondisi keseimbangan (equilibrium state), digunakan persamaan :

$$
\mathrm{E}_{\mathrm{OPH}}=1 / 2(\mathrm{a} / \mathrm{R})
$$

d. Melakukan estimasi Maximum Sustainable Yield (MSY) sebagai indikator potensi sumberdaya perikanan tangkap yang berkelanjutan (lestari) melalui persamaan:

MSY $=1 / 4$ (a / R)

Nilai effort optimum dan MSY yang diperoleh melalui persamaanpersamaan di atas, selanjutnya dimasukkan sebagai kendala tujuan dalam model ekonomi sumberdaya perikanan tangkap (model dasar LGP). Dengan demikian, secara biologi pengelolaan perikanan menunjukkan optimalisasi pemanfaatan sumberdaya perikanan tangkap yang berkelanjutan.

\section{HASIL DAN PEMBAHASAN}

Penangkapan ikan tongkol di Selat Makassar Sulawesi Selatan oleh nelayan di Kota/Kabupaten : Makassar, Maros, Pangkep, Parepare, Barru, dan Pinrang biasanya menggunakan alat tangkap seperti pada Tabel 1.

Gambaran produksi hasil tangkapan untuk kelima belas alat tangkap yang digunakan untuk menangkap ikan tongkol di Selat Makassar Sulawesi Selatan tahun 1999 - 2007 pada Tabel 1, terlihat pada gambar 1. Produksi ikan tongkol per alat tangkap per tahun dimana produksi alat tangkap tertinggi adalah pukat cincin kemudian berturut-turut sesuai ranking : bagan perahu, payang, jaring insang tetap, pancing lain, pancing tonda, jarring insang hanyut, jarring lingkar, bagan tancap, pukat pantai, alat penangkapan ikan lainnya, jaring angkat lain, rawai tetap, rawai hanyut dan huhate
Tabel 1. Jenis alat tangkap untuk ikan tongkol di Selat Makassar Sulawesi Selatan Tahun 1999-2007

\begin{tabular}{cl} 
No & \multicolumn{1}{c}{ Jenis Alat Tangkap } \\
\hline 1 & Payang/Lampara \\
2 & Pukat Pantai/Beach seine \\
3 & Pukat Cincin/Purse seine \\
4 & Jaring insang Hanyut \\
5 & Jaring lingkar(EG Net) \\
6 & Jaring insang tetap \\
7 & Bagan Perahu \\
8 & Bagan Tancap \\
9 & Jaring angkat lainnya \\
10 & Rawai Hanyut \\
11 & Rawai Tetap \\
12 & Huhate \\
13 & Pancing Lain \\
14 & Pancing Tonda \\
15 & Lain-lain-Others \\
\hline Sumber: & Dinas Kelautan dan Perikanan Propinsi \\
& Sulawesi Selatan, 2010
\end{tabular}

Dengan dasar pertimbangan standarisasi effort yang digunakan adalah : 1) respon stock terhadap alat tangkap standar akan menentukan status sumberdaya selanjutnya berdampak pada status perikanan alat tangkap lain, 2) total hasil tangkap ikan per unit effort alat tangkap standar lebih dominan dibanding alat tangkap lain, dan 3) daerah penangkapan alat tangkap standar meliputi dan atau berhubungan dengan daerah penangkapan alat tangkap lain, maka dari semua alat tangkap yang digunakan untuk menangkap ikan tongkol di perairan Selat Makassar Sulawesi Selatan di atas, alat tangkap Pacing Tonda dengan jumlah tangkapan dari tahun 1999-2007 yaitu $1.511,5820$ ton dengan nilai CPUE tertinggi $=0,04127525$, dijadikan sebagai standar sehingga prosedur analisis estimasi harus menggunakan alat tangkap standar yang ditentukan berdasarkan nilai Fishing Power Index (FPI) tertinggi. 
Estimasi potensi sumberdaya ikan tongkol dilakukan dengan cara menganalisis data total hasil tangkapan dan upaya penangkapan ikan dari beberapa jenis alat tangkap. Hasil yang diperoleh dari estimasi merupakan jumlah tangkapan ikan tongkol maksimum yang diperbolehkan agar ketersediaan sumberdaya perikanan tetap lestari (berkelanjutan) atau MSY (tabel 2).

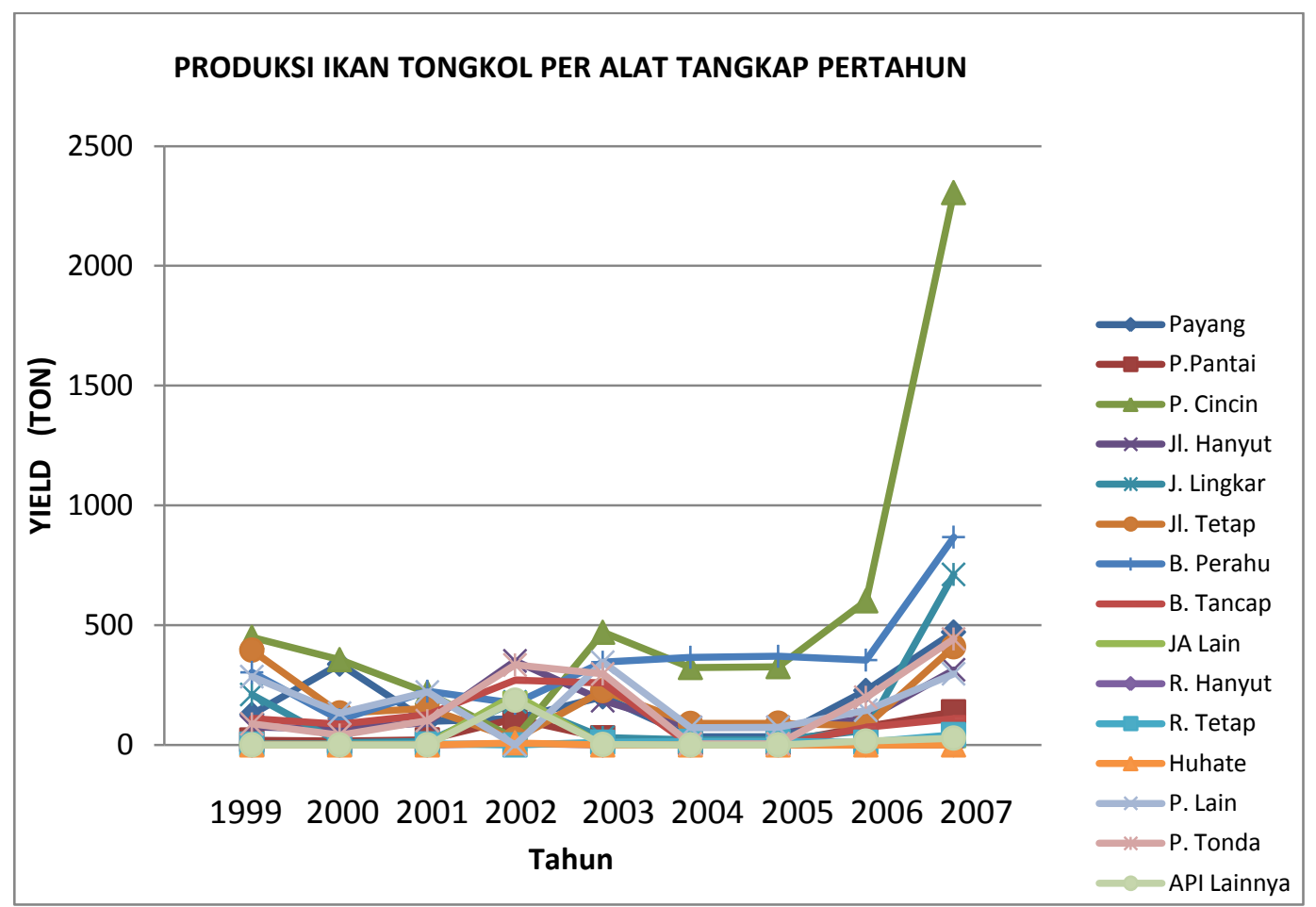

Gambar 1. Produksi ikan tongkol per alat tangkap per tahun

Dengan dasar pertimbangan standarisasi effort yang digunakan adalah : 1) respon stock terhadap alat tangkap standar akan menentukan status sumberdaya selanjutnya berdampak pada status perikanan alat tangkap lain, 2) total hasil tangkap ikan per unit effort alat tangkap standar lebih dominan dibanding alat tangkap lain, dan 3) daerah penangkapan alat tangkap standar meliputi dan atau berhubungan dengan daerah penangkapan alat tangkap lain, maka dari semua alat tangkap yang digunakan untuk menangkap ikan tongkol di perairan Selat Makassar Sulawesi Selatan di atas, alat tangkap Pacing Tonda dengan jumlah tangkapan dari tahun 1999-2007 yaitu
$1.511,5820$ ton dengan nilai CPUE tertinggi $=0,04127525$, dijadikan sebagai standar sehingga prosedur analisis estimasi harus menggunakan alat tangkap standar yang ditentukan berdasarkan nilai Fishing Power Index (FPI) tertinggi.

Estimasi potensi sumberdaya ikan tongkol dilakukan dengan cara menganalisis data total hasil tangkapan dan upaya penangkapan ikan dari beberapa jenis alat tangkap. Hasil yang diperoleh dari estimasi merupakan jumlah tangkapan ikan tongkol maksimum yang diperbolehkan agar ketersediaan sumberdaya perikanan tetap lestari (berkelanjutan) atau MSY (tabel 2) 


\begin{tabular}{rrrrr}
\hline Tahun & Catch (ton) & Effort Standart (F) & \multicolumn{1}{c}{ CPUE } & \multicolumn{1}{c}{ LNCPUE } \\
\hline 1999 & 2071.9970 & 1078968.3450 & 0.00192035 & -6.25524777 \\
2000 & 1291.3 & 1470138.8800 & 0.000878352 & -7.037462689 \\
2001 & 1280.1902 & 492661.7362 & 0.002598518 & -5.952814111 \\
2002 & 1881.6 & 401875.2688 & 0.00468205 & -5.364019285 \\
2003 & 2403.3 & 572327.7214 & 0.004199168 & -5.472868974 \\
2004 & 1009.5 & 3133218.4820 & 0.000322193 & -8.040360865 \\
2005 & 1020.7 & 7869870.6230 & 0.000129697 & -8.950308236 \\
2006 & 1954.6 & 105202.7766 & 0.018579358 & -3.985704124 \\
2007 & $\mathbf{6 1 3 9 . 6}$ & 148747.7540 & 0.041275245 & -3.187492352 \\
\hline
\end{tabular}

Sumber : diolah dari data primer

Tabel 2, menunjukkan bahwa jumlah tangkapan ikan tongkol pada tahun 1999 sebesar 2.071,9970 ton. Pada tahun 2000 terjadi penurunan produksi sebanyak 1.291,3000 ton, kemungkinan disebabkan karena kurangnya jumlah tangkapan. Pada tahun 2001 terjadi penurunan jumlah tangkapan ikan tongkol sebanyak 1.280,1902 ton dibanding tahun 2000, kemungkinan disebabkan karena kurangnya jumlah jumlah trip (effort). Pada tahun 2002 terjadi peningkatan jumlah tangkapan ikan tongkol sebesar 1.881,6 ton jika dibandingkan tahun 2001, kemungkinan disebabkan karena banyaknya stok ikan. Tahun 2003 terjadi peningkatan jumlah tangkapan ikan tongkol dimana produksi yang dihasilkan sebesar 2.403,3 ton, kemungkinan hal ini disebabkan meningkatnya jumlah trip (effort) yaitu sebanyak 572.327,7214 dibanding tahun 2002 yang hanya sebanyak 401.875,2688. Tahun 2004 produksi tangkapan ikan tongkol sangat menurun sebesar 1.009,5 ton karena masih tingginya jumlah trip. Tahun 2005 terjadi peningkatan penangkapan ikan tongkol sebanyak 1.020,7 ton kemungkinan disebabkan oleh penambahan trip (effort) sebanyak 7.869.870,6230 jika dibandingkan dengan tahun 2004 sebesar 3.133.218,4820 ton. Pada tahun 2006 terjadi peningkatan jumlah hasil tangkapan ikan tongkol sebesar 1.954,6 ton kemungkinan karena kehadiran stok ikan sesuai waktu ruayanya. Pada tahun 2007 terjadi peningkatan hasil tangkapan ikan tongkol sebesar 6.139,6 ton, dan hasil tangkapan ini melebihi tahun-tahun sebelumnya (1999-2006) hal ini kemungkinan disebabkan oleh meningkatnya jumlah trip (effort) sebesar $148.747,7540$ jika dibandingkan tahun 2006 sebesar 105.202.7766.

Dilihat dari nilai Catch Per Unit Effort (CPUE) mengalami fluktuasi turun naik. Nilai CPUE yang diperoleh pada tahun 1999 sebesar 0.00192035 yang berarti bahwa produksi ikan Tongkol pada tahun tersebut sebanyak 0.00192035 ton per trip. Nilai CPUE pada tahun 2000 mengalami penurunan sebesar 0.000878352 ton per trip sedangkan pada tahun terakhir 2007 mengalami peningkatan memuncak sebesar 0.041275245 ton per trip. Hal tersebut terjadi kelebihan penangkapan karena jumlah effort standar meningkat sehingga jumlah hasil produksi tangkapan meningkat pula.

Dengan data catch (ton) pada Tabel 2 di atas, dibandingkan dengan nilai MSY model Fox pada Tabel 3 di bawah ini diperoleh jumlah catch (ton) yang diperbolehkan dan effort optimum (unit penangkapan) yang diperbolehkan. 
Tabel 3. Potensi Lestari Maksimum dan Effort Optimum Ikan tongkol di perairan Selat Makassar Sulawesi Selatan Tahun 1999 - 2007 berdasarkan metode Scheafer dan Fox.

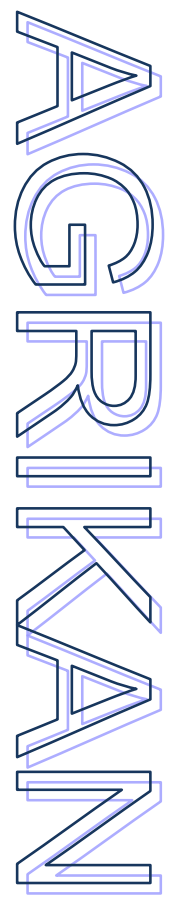

\begin{tabular}{ccrrr}
\hline No & Nilai & \multicolumn{1}{l}{ Scheafer } & \multicolumn{1}{l}{ Fox } & Satuan \\
\hline 1 & $a$ & 0.0119 & -5.015 & \\
2 & $b$ & $-2 \mathrm{E}-09$ & -0.0000006 & \\
3 & $M S Y$ & 17701.25 & 4069.75 & Ton \\
4 & Fopt & 2975000 & 16666666.667 & Trip \\
5 & $\mathrm{R}^{2}$ & 0.1563 & 0.6666 &
\end{tabular}

Sumber : diolah dari data primer

Dari Tabel 3, diperlihatkan nilai persamaan regresi sederhana dengan nilai a dan $b$, juga diperlihatkan nilai MSY, $F_{\text {opt }}$ dan $\mathrm{R}^{2}$ berdasarkan model Scheafer dan Fox. Berdasarkan nilai $\mathrm{R}^{2}$ maka model Fox yang dipakai sebagai standar MSY dan Fopt karena nilai $\mathrm{R}^{2}=0,666$ mendekati angka 1 (artinya hubungan keeratan antara produksi dan effort lebih kuat) jika dibandingkan dengan model Scheafer dengan nilai $\mathrm{R}^{2}=0,1563$ jauh dari angka 1 .
Jadi nilai catch (ton) pada Tabel 2 diatas jika dibandingkan dengan nilai MSY model Fox $=4.069,75$ ton pada Tabel 3, maka catch pada tahun 1999 - 2006 belum mengalami over fishing karena nilainya belum melebihi nilai MSY $=4.069,75$ ton . Over fishing baru terjadi pada tahun 2007 karena catch $=6.139,6$ ton $>$ MSY $=$ $4.069,75$ ton. Untuk lebih jelasnya bisa dilihat pada Gambar 2.
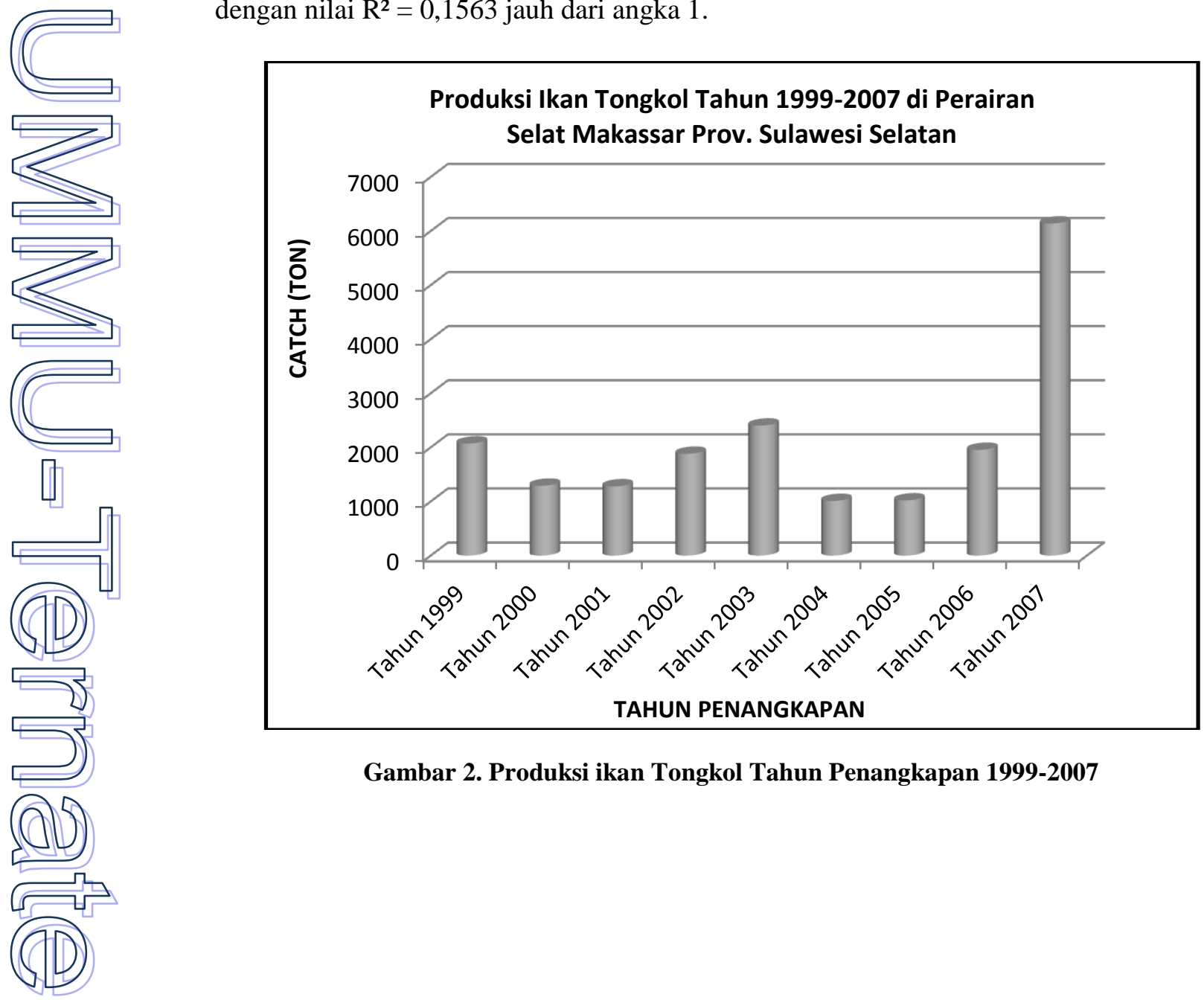

Gambar 2. Produksi ikan Tongkol Tahun Penangkapan 1999-2007 
Gambar 2, terlihat bahwa catch yang diperoleh pada tahun penangkapan 1999-2006 belum melebihi nilai MSY $=4.069,75$ ton, Tetapi pada tahun 2007 catch mencapai 6.139.6 ton telah melebihi nilai $\mathrm{MSY}=4.069,75$ ton menunjukan telah terjadi over fishing.
Untuk itu, dengan grafik pada Gambar 13 dijelaskan hubungan nilai MSY dengan upaya penangkapan (Effort optimum) agar sumberdaya ikan tetap lestari dan upaya penangkapan tidak merugikan nelayan.

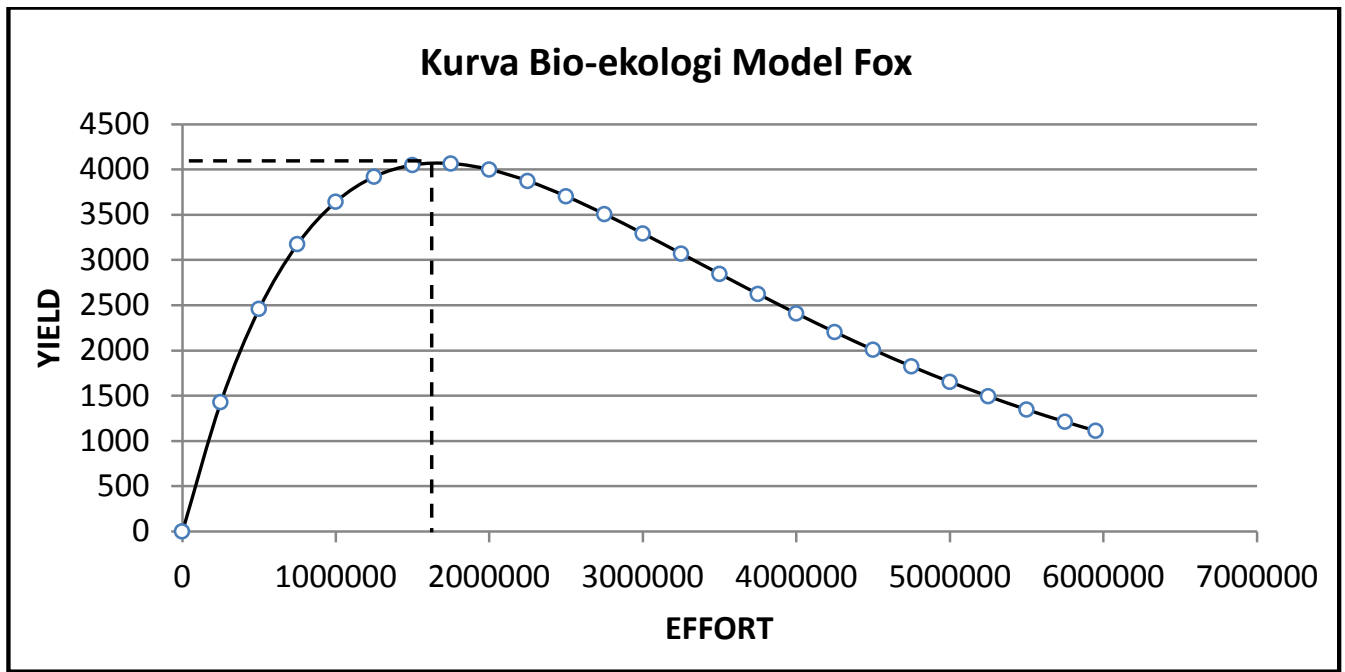

Gambar 3. Grafik MSY dan Effort Optimum Model Fox

Dari gambar 3 di atas, terlihat jelas bahwa dengan nilai MSY $=4.069,75$ ton dan Fopt $=1.666 .666,667$ trip maka terjadi keseimbangan antara upaya penangkapan (effort) dengan hasil penangkapan ikan tongkol yang diperoleh (Yield). Jika ditambahkan upaya penangkapan (trip) maka hasil penangkapan ikan tongkol yang diperoleh akan semakin menurun hingga mendekati angka nol. Dimana pada kondisi yang demikian telah terjadi banyak kerugian, baik dari segi biaya yang dikeluarkan (ekonomi) maupun pemulihan stok ikan tongkol (biologi).

\section{PENUTUP}

\subsection{Kesimpulan}

Dari hasil dan pembahasan, dapat disimpulkan bahwa :

1. Nilai lestari (Maximum Sustainable Yield) ikan tongkol di Selat Makassar Sulawesi Selatan adalah 4.069,75 ton per tahun dengan penangkapan optimum 1.666.666,67 trip per tahun.

2. Keberadaan populasi ikan Tongkol di perairan Selat Makassar Sulawesi Selatan telah mengalami over fishing, dimana hasil penangkapan pada tahun 2007 sebesar 6.139.6 ton telah melewati nilai lestari (MSY) ikan tongkol sebesar 4.069,75 ton per tahun.

\subsection{Saran}

Dari kesimpulan di atas, disarankan :

1. Perlu diadakan pembatasan terhadap jumlah effort yang beroperasi untuk menangkap ikan Tongkol di Selat Makassar Sulawesi Selatan.

2. Diharapkan kerjasama Dinas Kelautan dan Perikanan Propinsi Sulawesi Selatan dengan Dinas Kelautan dan Perikanan Kota/Kabupaten : Makassar, Maros, Pangkep, Barru, Pare-Pare dan Pinrang untuk membuat data hasil tangkapan dan trip yang lebih akurat. 


\section{DAFTAR PUSTAKA}

DKP, 1999 - 2007., Data Produksi Hasil Perikanan Provinsi Sulawesi selatan. Data Statistik Dinas Kelautan Perikanan Provinsi Sulawesi Selatan Tingkat I.

Mallawa A., 2006. Pengelolaan Sumberdaya Ikan Berkelanjutan Dan Berbasis Masyarakat. Disajikan pada lokakarya Agenda Penelitian Program COREMAP II Kabupaten Selayar, 9-10 September 2006.

Nazir, 2003. Metode Penelitian. Cetakan Kelima, Penerbit Ghalia Indonesia.

Nikijuluw, 2002. Rezim Pengelolaan Sumberdaya Perikanan. Cetakan Pertama Penerbit : PT Pustaka Cidesindo.

Per Sparre dan Siebren C Venema, 1999. Introduksi Pengkajian Stok Ikan Tropis. Pusat Penelitian dan Pengembangan Perikanan

Sudirman dan Mallawa, 2004. Teknik Penangkapan Ikan. Cetakan Pertama, Penerbit Rineka Cipta.

Widodo J, Suadi, 2006. Pengelolaan Sumberdaya Perikanan Laut. Gadjah Mada University Press.

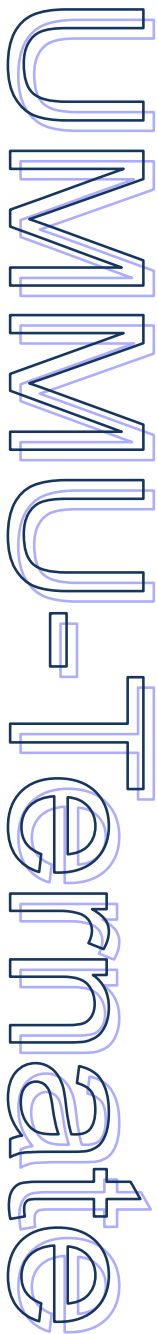

